\title{
PROPOSTA DE PROJETO INTEGRADOR PARA O DESENVOLVIMENTO DE COMPETÊNCIAS EMPREENDEDORAS EM UMA FACULDADE DE TECNOLOGIA
}

\section{INTEGRATIVE PROJECT PROPOSAL FOR DEVELOPING ENTREPRENEURIAL SKILLS IN A TECHNOLOGY COLLEGE}

Glauco Wender Caetano - glauco.caetano@gmail.com Faculdade de Tecnologia de São Carlos - São Carlos - SP - Brasil

Ana Teresa Colenci Trevelin - ana.trevelin@fatec.sp.gov.br Faculdade de Tecnologia de São Carlos - São Carlos - SP - Brasil

DOI: 10.31510/infa.v18i1.1133

Data de submissão: 16/04/2021

Data do aceite: 09/07/2021

Data da publicação: 30/07/2021

\begin{abstract}
RESUMO
O objetivo desta pesquisa foi analisar um projeto integrador em educação empreendedora, utilizando-se das Atividades Autônomas de Projeto da Fatec São Carlos, no intuito de desenvolver competências empreendedoras, como liderança, resolução de problemas, proatividade, criatividade e um processo de ensino-aprendizagem mais interdisciplinar, inovador e participativo. A pesquisa teve como suporte metodológico a abordagem qualitativa, tendo como característica um estudo exploratório-descritivo desenvolvido através de uma revisão bibliográfica que aborda a educação empreendedora e a aprendizagem baseada em projetos. Como resultado, propõe-se discutir a atualização da metodologia utilizada nas AAPs com a adoção de novos métodos interdisciplinares, como os princípios da aprendizagem baseada em projetos e a utilização de hackathons no ambiente acadêmico, que proporcionem um aprendizado superior a elaboração de planos de negócios e que incluam o desenvolvimento de competências empreendedoras nos alunos das Faculdades de Tecnologia. Com isso, esperase que a proposta desperte ainda mais nos estudantes a importância do empreendedorismo.
\end{abstract}

Palavras-chave: Empreendedorismo. Educação Empreendedora. Projeto Integrador. Aprendizagem baseada em Projetos. Hackathon.

\begin{abstract}
The objective of this research was to analyze an integrative project in entrepreneurial education, using Fatec São Carlos Autonomous Project Activities, in order to develop entrepreneurial skills, such as leadership, problem solving, proactivity, creativity and a teaching-learning process more interdisciplinary, innovative and participatory. The research had as methodological support the qualitative approach, having as characteristic an exploratory-
\end{abstract}


descriptive study developed through a bibliographic review that addresses entrepreneurial education and project-based learning. As a result, it is proposed to discuss the updating of the methodology used in the AAPs with the adoption of new interdisciplinary methods, such as the principles of project-based learning and the use of hackathons in the academic environment, which provide superior learning in the elaboration of business plans and that include the development of entrepreneurial skills in the students of the Faculties of Technology. With this, it is expected that the proposal will further awaken in students the importance of having their own business.

Keywords: Entrepreneurship. Entrepreneurial education. Integrative Project. Project-Based Learning. Hackathon.

\section{INTRODUÇÃO}

Para a economia, a geração de renda e a sociedade, evidenciar o empreendedorismo é cada vez mais importante (LOPES, 2010). No intuito de combater o desemprego e gerar crescimento econômico, as políticas públicas criadas pelos governos e sociedades interessamse cada vez mais pelo destacado fenômeno socioeconômico, o empreendedorismo, por causa da abertura de novas empresas e a criação de empregos, que geram renda (ROCHA; FREITAS, 2014). Além disso, a pandemia do COVID 19 também evidencia, por causa da grave crise econômica e social, a importância de ensinar as pessoas a desenvolverem meios de geração de renda própria.

Com isso, torna-se extremamente relevante o papel das instituições de ensino e dos educadores para incentivar os alunos a explorarem o potencial empreendedor do país e desenvolver um novo perfil profissional, que atenda o desejo empreendedor dos brasileiros. $\mathrm{Na}$ maioria das faculdades da área de gestão e administração, o ensino ainda é voltado para o preparo de funcionários para carreiras em grandes empresas. Através de métodos diferentes dos tradicionais, é possível aprender a ser empreendedor. (DOLABELA, 2008). Mas como ensinar as pessoas a empreenderem? Como abordar o empreendedorismo nos cursos de Gestão?

Lopes (2010) acredita que ensinar a fazer plano de negócios pelos professores não contribui para que o aluno aprenda a ser empreendedor, conforme o modelo importado americano. Por isso, o presente trabalho, ao analisar uma proposta de projeto interdisciplinar, que contemple as competências empreendedoras e a aprendizagem baseada em projetos, nas disciplinas de Atividades Autônomas de Projetos, justifica-se, pois contribui para uma abordagem de ensino mais inovadora, que contemple o desenvolvimento de habilidades 
essenciais para quem deseja empreender, indo além da elaboração de planos de negócios e que fomente o sonho de empreender dos estudantes, gerando emprego e renda.

O estudo parte da identificação de componentes curriculares da Fatec São Carlos, tendo como objetivo geral analisar um projeto integrador que contribua para o desenvolvimento de competências empreendedoras nas Faculdades de Tecnologia, por meio das disciplinas de Atividades Autônomas de Projetos (AAPs).

\section{EDUCAÇÃO EMPREENDEDORA}

Ao realizar pouco para criar atividades empreendedoras, o sistema educacional agrava a situação dos estudantes, pois estes passam grande parte de seu tempo nos estudos, mas não possuem, em sua maioria, experiência para dirigir e montar um negócio (ROBERTSON et al. 2003). Barreto (1998) afirma que ao incompreender as vantagens da educação empreendedora como política de desenvolvimento econômico e social, ao dificultar o acesso ao crédito, a insuficiência das tecnologias, ao precarizar o nível educacional e disponibilizar pouco capital, o contexto brasileiro oferece muito pouco ou quase nada.

Incentivar os alunos a explorarem o potencial empreendedor do país e contribuir para o desenvolvimento de uma educação empreendedora cabe às instituições de ensino e aos educadores, já que há a necessidade de criar um novo perfil profissional e atender o desejo empreendedor dos brasileiros (DA COSTA; WOLF; RIBEIRO, 2006). Para que possam surgir as boas ideias, é necessário desenvolver nos alunos suas capacidades empreendedoras, ou seja, transformar o conhecimento produzido na universidade em produto ou serviço. (SOUZA et al., 2005).

Ocupar vagas em grandes organizações, trabalhos em profissões técnicas ou atuar como profissionais liberais são os modelos idealizados historicamente pelos sistemas educacionais (DA SILVA; PATRUS, 2017). Dolabela (2008) corrobora com essa posição ao afirmar que a maioria dos currículos escolares são inspirados pelas descrições de cargos, voltados para as competências para a indústria e visando o atendimento das necessidades do modelo industrial.

$\mathrm{Na}$ maioria das faculdades de Administração ainda é presente o desejo de preparar funcionários para carreiras em grandes empresas (LOPES, 2010). Com a formação voltada a profissionais que irão buscar emprego no mercado de trabalho, o ensino de empreendedorismo no Brasil ainda é incipiente (DOLABELA, 2008). 


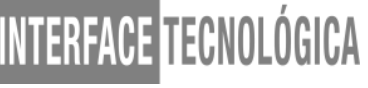

O que se aprende na escola, no conceito tradicional, não se incluem nos fundamentos do empreendedor (DOLABELA, 2008). Por isso, uma educação específica voltada para o empreendedorismo tem sido iniciada em diversas universidades e escolas em todo o mundo. (DORNELAS, 2015).

Identificar e explorar oportunidades de negócios, no intuito de desenvolver habilidades empreendedoras, treinar os alunos para a abertura de uma empresa e administrá-la e desenvolver o espírito empreendedor entre os alunos são os três objetivos da estrutura para a educação empreendedora no ensino superior apresentada pelo European Commission Enterprise and Industry Directorate-General (EUROPEAN COMMISSION, 2008).

Aprender a aprender, a ser, a fazer e conviver, são competências mais necessárias que a aquisição de conhecimentos para a criação de uma metodologia para o desenvolvimento das habilidades empreendedoras (SOUZA et al., 2005). Lopes (2010) afirma que o aluno deve aprender com experiências, aprender com o processo de pensar de maneira diferente ao se deparar com eventos críticos, ou seja, o aprender fazendo como metodologia de ensino.

Lopes (2010) acredita que ensinar a fazer plano de negócios pelos professores não contribui para que o aluno aprenda a ser empreendedor, conforme o modelo importado americano. É desafiante encontrar um meio de padronizar os programas e cursos de empreendedorismo, já que há diferentes cursos sobre o tema, diferentes formas de rotular e diferentes significados de uso do empreendedorismo pelas universidades em inúmeras agendas (VESPER; GARTNER, 1997).

A construção da qualidade de vida para todos, do humano e do social devem substituir a lógica do individualismo e do utilitarismo, pois a educação constrói um mundo melhor ao despertar a força da inovação, a rebeldia e a criatividade (DOLABELA, 2003). Para destruir mitos que impedem o desenvolvimento de uma sociedade cidadã e realizar utopias que quebrem antigos paradigmas, a universidade deve proporcionar ao aluno uma rede de saberes inter-relacionados (LOPES, 2010).

Por fim, o estímulo do ensino de empreendedorismo pode causar o crescimento da geração de empregos e da economia local, o que é corroborado pelas diversas pesquisas em países que possuem rápido crescimento econômico e baixas taxas de desemprego por apoiarem e incentivarem novos empreendedores (DORNELAS, 2015). 


\section{INTERDISCIPLINARIDADE E APRENDIZAGEM BASEADA EM PROJETOS}

Para repensar, de maneira contextualizada e mais articulada, a escola e a sociedade, o currículo interdisciplinar se coloca como uma possibilidade. Para uma nova configuração do currículo, a visão mais "conteudista" do ensino, que prioriza os conteúdos e a forma, presente no contexto social anterior à Revolução Industrial, deverá ser revisada, para que além da produção de novos saberes contextualizados, não ocorra uma fragmentação curricular ao abordar a noção de realidade e do mundo de trabalho (SANTOS; BARRA, 2012).

De acordo com Behrens (2006), ao buscar uma visão mais holística e flexível, o ensino de empreendedorismo torna-se um método interessante ao relacionar-se com a interdisciplinaridade. Uma alternativa importante para o ensino interdisciplinar é a abordagem de projetos, que ainda se mantém após décadas da proposição original do método de Kilpatrick (GARCIA, 2012).

Na Era Contemporânea, os precursores da Aprendizagem baseada em Projetos são John Dewey e William H. Kilpatrick, ambos do século XX. Dewey acreditava que a ajuda do professor era essencial para os projetos realizados pelos alunos, para que garantisse o processo contínuo de crescimento e aprendizagem.

Ao preparar a aprendizagem ao longo da vida, vincular a aprendizagem a situações e problemas reais, a aprendizagem baseada em projetos mantém uma formação de indivíduos com uma visão global da realidade (HERNANDÉZ; VENTURA, 1998).

De acordo com Moura e Barbosa (2011), as diretrizes fundamentais para o desenvolvimento de projetos de trabalho são: projetos com número de participantes definidos de forma criteriosa para cada experiência, ou seja, grupos de alunos; definição de tempo para a realização do projeto; negociação entre alunos e professores, considerando interesses múltiplos e os objetivos didáticos, para a escolha do tema; projetos que contemplem uma finalidade útil de modo que os alunos tenham uma percepção de sentido real dos projetos propostos; utilização de múltiplos recursos no desenvolvimento dos projetos, dentro ou fora do ambiente escolar; comunicação e socialização dos resultados em diversos níveis, seja na sala de aula, a escola ou a comunidade.

Os trabalhos realizados durante o semestre letivo, de caráter interdisciplinar, que possuem o objetivo de integrar as áreas de conhecimento, no intuito de criar uma proposta de projeto que envolva duas ou mais disciplinas de um mesmo período letivo e que articule os 
conhecimentos já adquiridos pelos estudantes, é denominado de Projeto Integrador (SANTOS; BARRA, 2012).

\section{PROCEDIMENTOS METODOLÓGICOS}

Para a realização deste trabalho, o procedimento inicial foi a realização de uma pesquisa bibliográfica, a fim de aumentar o domínio do conhecimento disponível sobre o tema e constituir um referencial teórico, tendo como base a consulta de livros, artigos e periódicos que abordam a temática da educação empreendedora no ensino superior, acompanhada de uma proposta de aplicação de um projeto integrador que envolva as Atividades Autônomas de Projeto, que são disciplinas estruturantes dos cursos de Gestão Empresarial das Fatecs.

Em relação ao objetivo, a presente pesquisa é exploratória, conforme Prodanov e Freitas (2013), já que esta possui como finalidade o ajustamento das informações sobre o objeto investigado, o que possibilita sua definição e seu delineamento, assim como a orientação da definição do objetivo e a formulação de proposições, visando assumir, em um contexto geral, as formas de estudos de casos e pesquisas bibliográficas.

Além disso, é exploratória de natureza aplicada, ao buscar uma solução prática para as dificuldades de uma comunidade específica, a Fatec São Carlos. A partir da revisão bibliográfica, foi empregado o método de estudo de caso, já que a proposta foi construída a partir da reflexão da importância do tema e da análise e discussão das possíveis propostas, a fim de aprimorar a atual estrutura curricular. Neste artigo, é realizado uma análise do Projeto Pedagógico e o Manual do Projeto Interdisciplinar do Curso de Gestão Empresarial, assim como o estudo de trabalhos acadêmicos que abordam os conceitos de empreendedorismo, educação empreendedora, projeto integrador, aprendizagem baseada em projetos e hackathon, tendo como visão a identificação de fatores que possam contribuir para a proposta de um projeto integrador nas Atividades Autônomas de Projeto na Fatec São Carlos.

Durante o período de pesquisa bibliográfica e análise documental, foram efetuadas pesquisas com as seguintes palavras chaves: empreendedorismo, entrepreneurship, educação empreendedora, pedagogical entrepreneurship, projeto integrador, aprendizagem baseada em projetos e hackathon nas bases de dados do Scielo e Google Scholar (2000 a 2019).

Entre os vários textos pesquisados, foram notados conceitos ligados à temática pertinente a pesquisa, como empreendedorismo e educação empreendedora, tendo como destaque Dolabela 


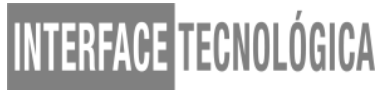

(2008), Lopes (2010) e Dornelas (2015). É notável também a contribuição de Moura e Barbosa (2011) com o conceito de Aprendizagem baseada em Projetos e Santos e Barra (2012) para as ponderações sobre interdisciplinaridade.

\section{PROPOSTA DE PROJETO INTEGRADOR COM AS AAPs}

Baseando-se nos principais conceitos sobre educação empreendedora e nos ideais da aprendizagem baseada em projetos, o objeto de estudo proposto terá como objetivo o desenvolvimento, nos alunos da Faculdade de Tecnologia de São Carlos, das capacidades e aptidões tão necessárias para o empreendedorismo.

De acordo com Trevelin, Neto e Caetano (2020), a unidade, ao notar as reestruturações curriculares nos cursos de Tecnologia em Gestão Empresarial, sentiu a necessidade de revisar algumas matrizes curriculares nas Atividades Autônomas de Projeto (AAPs), todas previstas no Inciso VII do artigo $9^{\circ}$ do Regulamento de Graduação das FATECs.

Por meio deste estudo é proposto um projeto integrador, cuja construção permitirá aos alunos, semestralmente, durante as 60 horas contidas nas Atividades Autônomas de Projeto, elaborar um projeto que contemple as disciplinas do semestre vigente, seguindo o tema proposto. O projeto integrador possuirá, em sua estrutura, seis temáticas principais: Tecnologia, Social, Pessoas, Finanças, Produção e Ambiental (TREVELIN et al., 2020).

No intuito de desenvolver as competências e habilidades empreendedoras, cada projeto possuirá como estrutura as seis diretrizes essenciais da aprendizagem baseada em projetos, elucidadas por Moura e Barbosa (2011), que são: Trabalho em Grupo, Tempo, Escolha do Problema, Finalidade Útil, Múltiplos Recursos e Socialização dos Resultados.

Para Trevelin et al. (2020), a diretriz de Trabalho em Grupo focará no desenvolvimento de habilidades sociais, levando em consideração a figura do líder, a importância de comunicar-se e dividir as tarefas entre os membros, pois cada projeto contará com grupos de quatro ou cinco alunos; Para demonstrar a importância da gestão do tempo, a diretriz do Tempo focará no cumprimento de prazos, na elaboração de metas bem definidas, ser pontual na entrega dos resultados, já que cada projeto terá um tempo estipulado de 5 meses para ser desenvolvido; A Escolha do Problema, a terceira diretriz, contribuirá para que o estudante seja protagonista de sua própria educação e responsável pela escolha do problema que norteará seu projeto, conforme a temática definida para a AAP do semestre. Ao permitir que o estudante se torne 
autônomo no processo de ensino aprendizagem, o professor torna-se colaborador em sala de aula; Ao permitir a escolha de problemas reais enfrentados pelas empresas da cidade de São Carlos, a diretriz de Finalidade Útil encontra-se ligada à terceira diretriz, pois os problemas são reais, as soluções deverão ser pertinentes, com aplicações úteis, que permita uma aproximação maior do ambiente acadêmico com o setor empresarial; Já a diretriz de Múltiplos Recursos permitirá a utilização de inúmeros recursos que sejam pertinentes para a construção do projeto, como o Design Thinking e o Modelo de Negócios Canvas, sejam estes inclusos ou não no contexto escolar; A Socialização dos Resultados, sexta diretriz, contribuirá para o desenvolvimento das habilidades necessárias para uma boa oratória, já que as possíveis soluções devem ser discutidas em grupo, a fim de se encontrar um consenso e uma solução definitiva para o problema apresentado.

Hackathons, que são eventos destinados para solucionar problemas variados de forma inovadora, deverão ser adaptados para o formato de sala de aula e realizados para a apresentação dos resultados dos projetos desenvolvidos pelos grupos (TREVELIN et al., 2020).

\section{DISCUSSÃO}

A proposta do projeto integrador tem como precursor o curso de Tecnologia em Gestão Empresarial da Fatec São Carlos, especialmente nas disciplinas de Atividades Autônomas de Projeto, porém trata-se de um projeto a ser discutido e implantado em todas as Fatecs que tenham este mesmo curso e que atualmente passa por uma reestruturação, tendo esta proposta sendo discutida no comitê de coordenadores. O curso escolhido em questão apresenta em seu Plano Pedagógico, como um dos objetivos específicos, o intuito de desenvolver com os estudantes os conhecimentos, atitudes e habilidades que contribuam para o desenvolvimento regional e do país, por meio do empreendedorismo.

Conforme o Projeto Pedagógico (2010), o curso é dividido em 6 semestres, tendo como base em seu eixo formativo, as disciplinas básicas, como Matemática e Estatística, Economia e Comunicação e Expressão e as disciplinas profissionais, como Gestão Empresarial, Transversais e Logística. Visando uma formação interdisciplinar, dentro da Matriz Curricular, são desenvolvidos projetos semestralmente, em uma disciplina denominada Atividades Autônomas de Projetos, comumente chamada de AAPs. 


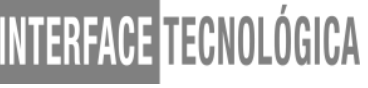

As AAPs, em seu formato atual, abrangem todas as disciplinas do curso, mas possuem algumas que são chaves, separadas por semestre, tendo sempre um docente responsável, com as respectivas horas-atividade para desenvolvimento do projeto. Conforme o Manual do Projeto Interdisciplinar do Curso de Gestão Empresarial (2015), as disciplinas chaves são: no primeiro semestre, Informática; no segundo semestre, Comportamento Organizacional; no terceiro, Organização, Sistemas e Métodos; no quarto, Planejamento de Marketing; no quinto, Gestão de Projetos Empresariais; e no sexto semestre, Desenvolvimento de Negócios.

Conforme o Manual do Projeto Interdisciplinar do Curso de Gestão Empresarial (2015), durante cada semestre, em disciplinas específicas, o grupo irá trabalhar tópicos do plano de negócios de forma que o resultado será o trabalho finalizado ao final do curso. Isso evidencia a necessidade de atualização das AAPs, de forma que a faculdade permita novos métodos, que vá além da elaboração de plano de negócios.

Outra fragilidade é o distanciamento da realidade vivida nas empresas com a própria faculdade, pois o estudante que será gestor deve conhecer as principais dificuldades enfrentadas pelas empresas. Essa posição é defendida por Alvarenga, Rodrigues e Lopes (2019), ao afirmar que os programas de educação empreendedora buscam desenvolver atitudes e habilidades para a utilização de técnicas de resolução de problemas relacionados ao ambiente empresarial.

\section{CONCLUSÃO}

Por meio do estudo teórico e das informações obtidas pelos componentes curriculares das Atividades Autônomas de Projeto, é notória a importância de discutir o empreendedorismo nas instituições de ensino superior e as melhores formas de abordá-lo em sala de aula. Com as recentes mudanças no mercado de trabalho, torna-se essencial o desenvolvimento de um novo perfil profissional, que exige novas competências, tais como: liderança, resolução de conflitos, criatividade e pensamento inovativo.

As Faculdades de Tecnologia, ao reestruturar o curso de Tecnologia em Gestão Empresarial, abrem espaço para discutir as melhores adequações curriculares que permitam uma abordagem didático-pedagógica interdisciplinar e inovadora, que vá de encontro aos anseios dos alunos que desejam empreender. As Atividades Autônomas de Projeto são essenciais em sua missão de desenvolver habilidades pertinentes que contribuam para a excelência da formação em gestão. 
Em seu modelo atual, as AAPs ainda promovem a elaboração de planos de negócios, mantidas pelas seis disciplinas básicas, como: Informática; Comportamento Organizacional; Organização, Sistemas e Métodos; Planejamento de Marketing; Gestão de Projetos Empresariais e Desenvolvimento de Negócios. Com isso, mesmo focando na interdisciplinaridade, é priorizada a abordagem exclusivamente do plano de negócios nas disciplinas básicas ou correspondentes do semestre. Perde-se também a oportunidade de ter contato com desafios reais enfrentados pelos empresários nas diversas áreas da gestão, já que a resolução de problemas empresariais não é bem trabalhada, focando somente na criação ou desenvolvimento de um produto ou empresa que responda a uma necessidade atual do mercado.

A proposta de projeto integrador busca promover uma discussão maior sobre as AAPs nas Faculdades de Tecnologia ao focar na importância do desenvolvimento de competências e habilidades empreendedoras, trazendo uma abordagem didático-pedagógica inovadora através dos princípios da aprendizagem em projetos. Com isso, passa-se de seis disciplinas básicas para seis temáticas básicas, que abrangem as principais áreas da gestão, como: Tecnologia, Social, Pessoas, Finanças, Produção e Ambiental; e adotando seis diretrizes da aprendizagem baseada em projetos: Trabalho em Grupo, Tempo, Escolha do Problema, Finalidade Útil, Múltiplos Recursos e Socialização dos Resultados. Somando as temáticas e as diretrizes, consegue-se promover o desenvolvimento de habilidades essenciais para o empreendedor, como: saber trabalhar em equipe, gestão do tempo, protagonismo, solução de problemas reais, o uso devido e responsável de inúmeros recursos, socialização, oratória, discussão de soluções e competitividade. Portanto, por meio desta proposta, as APPs conseguem desenvolver habilidades essenciais não só para quem deseja empreender, mas também para aqueles que desejam adotar o intraempreendedorismo no ambiente de trabalho, já que estas competências são essenciais e requeridas por qualquer empresa.

\section{REFERÊNCIAS}

ALVARENGA, P. S. R. et al. Proposta de Projeto Integrador resultante de estudo comparativo de modelos de educação empreendedora1. Revista Norte Científico, v.14, n.1, p. 115-149, 2019.

BARRETO, L. P. Educação para o empreendedorismo. Escola de Administração de Empresas da Universidade Católica de Salvador. Salvador -BA, 1998. 
BEHRENS, M. A. B. Paradigma da Complexidade. Metodologia de projetos, contratos didáticos e portfólios. Petrópolis. Vozes. 2006.

DA COSTA, P.; WOLF, S. M.; RIBEIRO, T. VA. Empreendedorismo e educação empreendedora: confrontação entre a teoria e prática. Revista de Ciências da Administração, v. 8, n. 15, p. 09-29, 2006.

DOLABELA, F. Pedagogia empreendedora. São Paulo: Editora de Cultura, 2003.

Oficina do empreendedor: a metodologia de ensino que ajuda a transformar conhecimento em riqueza. Rio de Janeiro: Sextante. 2008

DORNELAS, J. C. A. Empreendedorismo: transformando ideias em negócios. 5a ed.. Rio de Janeiro: Empreende / LTC, 2015.

EUROPEAN COMMISION ENTERPRISE AND INDUSTRY DIRECTORATE-GENERAL. (2008). Entrepreneurship in higher education, especially in non-business studies: final report of the expert group. Disponível em: https://ec.europa.eu/growth/content/entrepreneurship-higher-education-especially-withinnon-business-studies-0_nn. Acesso em: 28 mai. 2021.

FACUldade de TeCnOlOGia de SÃo CARLOS. Projeto Pedagógico do Curso de Tecnologia em Gestão Empresarial. Disponível em: http://www.fatecsaocarlos.edu.br/pdf/Projeto_Pedagogico.pdf. Acesso em: 28 mai. 2021.

FACULDADE DE TECNOLOGIA DE SÃO CARLOS. Manual do Projeto Interdisciplinar do Curso de Gestão Empresarial. Disponível em: http://www.fatecsaocarlos.edu.br/pdf/MANUAL\%20DO\%20PROJETO\%20INTERDISCIPL INAR\%20\%20v2.pdf. Acesso em: 28 mai. 2021.

GARCIA, J. O futuro das práticas de interdisciplinaridade na escola. Revista Diálogo Educacional, Curitiba, v.12, n.35, p.211 - 232, 2012. 
HERNANDEZ, F.; VENTURA, M. A organização do currículo por projetos de trabalho. Porto Alegre: Artmed, 1998.

LOPES, R. M. A. Educação empreendedora: conceitos, modelos e práticas. Elsevier, 2010.

MOURA, D. G; Barbosa, E. F. Trabalhando com projetos: planejamento e gestão de projetos. Editora Vozes, 2013.

PRODANOV, C.C.; FREITAS, E.C. Metodologia do trabalho científico: métodos e técnicas da pesquisa e do trabalho acadêmico. 2. ed. Novo Hamburgo: Feevale, 2013.

ROBERTSON, M. et al. Barriers to start-up and their effect on aspirant entrepreneurs.

Education + Training, v. 45, n. 6, p. 308-316, 2003.

ROCHA, E.L.C; FREITAS, A. A. F. Avaliação do ensino de empreendedorismo entre estudantes universitários por meio do perfil empreendedor. Revista de Administração contemporânea, v. 18, n. 4, p. 465-486, 2014.

SANTOS, M. C. C.; BARRA, S. R. O projeto integrador como ferramenta de construção de habilidades e competências no ensino de engenharia e tecnologia. In: COBENGE-XL Congresso Brasileiro de Ensino de Engenharia. Belém-Pa, 2012.

SOUZA, E.C.L. et al. Métodos, técnicas e recursos didáticos de ensino de empreendedorismo em IES brasileiras. Empreendedorismo além do plano de negócio. São Paulo: Editora Atlas, 2005 .

TREVELIN, A.T.C.; COLENCI NETO, A; CAETANO, G. Ecossistema Sancahub: Estratégias de Construção do Perfil e Capacitação do Jovem Empreendedor no caso de São Carlos. In: XV Simpósio dos Programas de Mestrado Profissional, São Paulo. Anais...São Paulo, 2020. 